\title{
Uric acid: association with rate of renal function decline and time until start of dialysis in incident pre-dialysis patients
}

\author{
Hakan Nacak ${ }^{1 *}$, Merel van Diepen ${ }^{1}$, Moniek CM de Goeij ${ }^{1}$, Joris I Rotmans², Friedo W Dekker ${ }^{1}$ \\ and the PREPARE-2 study group
}

\begin{abstract}
Background: In patients with chronic kidney disease (CKD) hyperuricemia is common. Evidence that hyperuricemia might also play a causal role in vascular disease, hypertension and progression of CKD is accumulating. Therefore, we studied the association between baseline uric acid (UA) levels and the rate of decline in renal function and time until start of dialysis in pre-dialysis patients.

Methods: Data from the PREPARE-2 study were used. The PREPARE-2 study is an observational prospective cohort study including incident pre-dialysis patients with CKD stages IV-V in the years between 2004 and 2011. Patients were followed for a median of 14.9 months until start of dialysis, kidney transplantation, death, or censoring. Main outcomes were the change in the rate of decline in renal function (measured as estimated glomerular filtration rate (eGFR)) estimated using linear mixed models, and time until start of dialysis estimated using Cox proportional hazards models.

Results: In this analysis 131 patients were included with a baseline UA level (mean (standard deviation (SD)) of $8.0(1.79) \mathrm{mg} / \mathrm{dl})$ and a mean decline in renal function of -1.61 (95\% confidence interval $(\mathrm{Cl}),-2.01 ;-1.22) \mathrm{ml} / \mathrm{min} /$ $1.73 \mathrm{~m}^{2} /$ year. The change in decline in GFR associated with a unit increase in UA at baseline was -0.14 (95\% $\mathrm{Cl}-0.61 ; 0.33, \mathrm{p}=0.55) \mathrm{ml} / \mathrm{min} / 1.73 \mathrm{~m}^{2} /$ year. Adjusted for demography, comorbidities, diet, body mass index (BMI), blood pressure, lipids, proteinuria, diuretic and/or allopurinol usage the change in decline in eGFR did not change. The hazard ratio (HR) for starting dialysis for each mg/dl increase in UA at baseline was $1.08(95 \% \mathrm{Cl}, 0.94 ; 1.24$, $\mathrm{p}=0.27)$. After adjustment for the same confounders the HR became significant at $1.26(95 \% \mathrm{Cl}, 1.06 ; 1.49, \mathrm{p}=0.01)$, indicating an earlier start of dialysis with higher levels of UA.
\end{abstract}

Conclusion: Although high UA levels are not associated with an accelerated decline in renal function, a high serum UA level in incident pre-dialysis patient is a risk factor for an earlier start of dialysis.

Keywords: Uric acid, CKD progression, Pre-dialysis, Prospective cohort

\section{Background}

Uric acid (UA) is an emerging risk factor for renal disease, hypertension, and cardiovascular disease. Hyperuricemia is common in patients with chronic kidney disease (CKD) and evidence that hyperuricemia may also play a causal role in hypertension, vascular disease and progression of CKD is accumulating [1-9]. In addition, some intervention studies have shown that treatment of hyperuricemia could

\footnotetext{
* Correspondence: h.nacak@lumc.nl

'Department of Clinical Epidemiology, Leiden University Medical Center, Albinusdreef 2, Leiden 2333 ZA, The Netherlands

Full list of author information is available at the end of the article
}

be beneficial for blood pressure regulation and preservation of kidney function $[10,11]$. Therefore, screening for hyperuricemia in CKD patients might help to identify patients that have an accelerated decline in renal function and thereby an increased risk for progression to ESRD.

The association between UA and decline in renal function has been investigated in several studies which included healthy individuals $[12,13]$, patients with CKD stages I-II $[14,15]$, patients with diabetes [6], and patients on peritoneal dialysis [16]. However, evidence about this association 
in patients with advanced CKD (stages IV-V) is scarce, and the effect on time until start of dialysis has not been addressed specifically.

The aim of our study is to investigate the association between baseline UA levels and the annual rate of decline in renal function and time until start of dialysis in CKD stage IV-V patients referred to specialized predialysis care. We hypothesize that UA in these patients is associated with accelerated decline in renal function and an earlier start of dialysis.

\section{Methods}

\section{Study design}

The association between UA and the annual rate of decline in renal function and time until start of dialysis was investigated in the ongoing PRE-dialysis PAtient REcord-2 (PREPARE-2) study, an observational prospective cohort study in incident pre-dialysis care patients. These patients were recruited from 25 nephrology outpatient clinics in the Netherlands. They were regularly seen by their nephrologist and treated in accordance with the treatment guidelines of the Dutch Federation of Nephrology, which are partly based on the K/DOQI and EBPG guidelines [17-20]. Data were collected in 6monthly intervals from the start of pre-dialysis care onwards. Patients were followed until start of dialysis, kidney transplantation, death or censoring. Patients were censored if they refused to further participate, if they moved to an outpatient clinic not participating in the PREPARE-2 study, if they were lost to follow-up, if their kidney function normalized, or if their follow-up was still continuing on February 12, 2013, whichever came first. The medical ethics committee or institutional review boards (when appropriate) of all participating centers approved this study (see Additional file 1: 'Ethical approval Prepare-2 study').

\section{Study population}

Patients were eligible for inclusion if they were 18 years or older and had been referred to a specialized predialysis outpatient clinic. In practice, this meant that the included pre-dialysis patients had an estimated glomerular filtration rate (eGFR) of less than $20-30 \mathrm{ml} / \mathrm{min} / 1.73 \mathrm{~m}^{2}$ accompanied by a progressive decline in renal function. Patients were also included if they had a failing transplant and had been transplanted at least one year ago. Prior to inclusion all patients gave written informed consent.

\section{Measurement and definitions}

In addition to the routine collection, laboratory data were also extracted from the electronic hospital information systems or medical records. The closest laboratory measurement performed within 90 days before or after the date of a visit was appointed to that visit. When no serum UA measurement was available on the first visit, but it was measured during the second visit, then this value was defined as the baseline value for UA. Variables used in the multivariable analysis were determined on the same visit as UA. Patients were regarded as hypertensive if a physician had diagnosed them as such. Proteinuria was defined as $>300 \mathrm{mg} /$ day protein in urine. The eGFR was calculated using the 4-variable Modification of Diet in Renal Disease (MDRD) formula, taking into account age, sex, black race, and serum creatinine [21].

\section{Outcomes}

The main outcomes are the change in rate of decline in renal function and time until start of dialysis per $\mathrm{mg} / \mathrm{dl}$ increase in baseline UA. To calculate the rate of decline in renal function, all available eGFR measurements from three months prior to inclusion until end of follow-up were used. In patients initiating dialysis, eGFR measurements until two weeks before the start of dialysis were used, because eGFR measurements after this point in time were no longer representative of true kidney function. Start of dialysis was defined as starting HD or PD during follow-up.

\section{Statistical analysis}

Continuous variables are presented as mean \pm standard deviation (SD), skewed variables are presented as median (boundaries of interquartile range, IQR) and categorical variables are presented as percentages. Baseline characteristics are presented for the total study population and stratified by patients below or above the median serum UA level at baseline.

A linear mixed model (LMM) was used to estimate the change in the rate of decline in renal function with each $\mathrm{mg} / \mathrm{dl}$ higher UA level at baseline [22]. In contrast to a standard linear model, the LMM takes into account that repeated eGFR measurements of the same patient are correlated. Multivariable analysis was used to adjust for potential confounders and we defined two adjusted models: age, sex, primary kidney disease, body mass index (BMI), presence of cardiovascular disease (CVD; angina pectoris, coronary disease, history of cerebrovascular accidents, heart failure, and/or myocardial infarction), ethnicity, hypertension, presence of diabetes mellitus (DM; type 1 and 2), protein restricted diet, systolic blood pressure (model 1) and model 1 plus low-density lipoprotein (LDL), cholesterol, proteinuria, diuretic use and allopurinol use (model 2) .

Kaplan-Meier analysis was performed to produce survival plots [23]. A Cox proportional hazards analysis was used to estimate the hazard ratio (HR) for starting dialysis with each $\mathrm{mg} / \mathrm{dl}$ higher UA level at baseline [24]. Follow-up time in this Cox proportional hazards analysis was the time between the baseline UA measurement and 
the start of dialysis. Mortality, kidney transplantation, loss to follow up, refusal of further participation, transfer to another outpatient clinic that doesn't participate in the PREPARE-2 study and follow-up continuing until at least February 12, 2013 were treated as censored events. The multivariable Cox analysis was adjusted for the same confounders as the LMM.

Missing values of potential confounders at baseline were imputed for patients with a baseline UA value using multiple imputation with 10 repetitions. The imputed data are predicted based on known information of each individual [25]. Besides the variables in model 1 and 2, diastolic blood pressure, high density lipoprotein, triglycerides, baseline eGFR, follow-up time and the endpoint reached (start of dialysis or not) were used for imputation. Followup time was skewed and was therefore logarithmically transformed before entering into the model.

Multiple sensitivity analyses were performed to test the robustness of our findings. First, we repeated our two main analyses without imputing missing confounder data. Second, alongside the main analysis (i.e. UA on a continuous scale) we dichotomized UA levels based on the normal values for UA (i.e. $7.06 \mathrm{mg} / \mathrm{dl}$ for men and 5.72 for women). Third, we added baseline eGFR levels to our models, in order to adjust for potential discrepancies in the eGFR at baseline.

$\mathrm{P}<0.05$ was considered statistically significant. All analyses were performed in PASW/SPSS version 20.0 for Windows.

\section{Results}

\section{Patient characteristics}

In total, 502 incident pre-dialysis patients were included in the PREPARE-2 study and prospectively followed. A total of 131 patients had a baseline UA measurement. Patients with a UA measurement at the first visit (0 months) did not differ from patients with a UA measurement at the second visit (6 months) (data not shown). Baseline characteristics for the total population and for patients with UA levels above and below the median are shown in Table 1. The 131 patients had a median UA level of 7.9 $\mathrm{mg} / \mathrm{dl}$ at baseline, mean (SD) age was 63.6 (14.6) years and $68.7 \%$ of the patients were male. If UA levels at baseline were above the median UA level, patients were more often male $(75.4 \%$ versus $62.9 \%)$. They were also more often hypertensive $(83.6 \%$ vs. $74.3 \%)$, had less often proteinuria $(66.7 \%$ vs. $85.7 \%)$, and used more often diuretics (55.7\% vs. $44.1 \%)$. Allopurinol was used less often in patients with UA levels above the median (4.9\% vs. $29.4 \%)$. Of the 19 variables that were used to impute missing data 9 were complete and 6 variables had less than 5\% missing data. On average the percentage of missing data per confounder was $7.7 \%$.
Table 1 Baseline characteristics for patients with UA levels above and below median and all patients

\begin{tabular}{|c|c|c|c|}
\hline & $\begin{array}{l}\mathrm{UA} \leq 7.9 \mathrm{mg} / \mathrm{dl} \\
\text { (median) } \\
(\mathrm{n}=70)\end{array}$ & $\begin{array}{l}\text { UA }>7.9 \mathrm{mg} / \mathrm{dl} \\
\text { (median) } \\
(\mathrm{n}=61)\end{array}$ & $\begin{array}{l}\text { Total } \\
(n=131)\end{array}$ \\
\hline $\mathrm{UA}(\mathrm{mg} / \mathrm{dl})(\mathrm{sd})$ & $6.69(0.89)$ & $9.5(1.32)$ & $8.0(1.79)$ \\
\hline Age (years) (sd) & $64.0(14.0)$ & $63.2(15.4)$ & $63.6(14.6)$ \\
\hline Sex $(\%$ male $)$ & 62.9 & 75.4 & 68.7 \\
\hline Ethnicity (\% caucasian) & 94.3 & 98.4 & 96.2 \\
\hline Diabetes (\%) & 20.0 & 19.7 & 19.8 \\
\hline \multicolumn{4}{|l|}{ PKD } \\
\hline$\%$ Diabetes & 7.1 & 9.8 & 8.4 \\
\hline$\%$ Glomerulonephritis & 12.9 & 13.1 & 13.0 \\
\hline$\%$ Renal vascular disease & 27.1 & 34.4 & 30.5 \\
\hline$\%$ Other & 52.9 & 42.6 & 48.1 \\
\hline Hypertension* (\%) & 74.3 & 83.6 & 78.6 \\
\hline BMI $\left(\mathrm{kg} / \mathrm{m}^{2}\right)(\mathrm{sd})$ & $26.3(4.8)$ & $25.0(3.9)$ & $25.7(4.4)$ \\
\hline CVD (\%) & 35.7 & 44.3 & 39.7 \\
\hline eGFR $(M D R D)^{* *}(s d)$ & $16.9(5.7)$ & $16.4(5.7)$ & $16.8(5.7)$ \\
\hline $\mathrm{SBP}(\mathrm{mm} \mathrm{Hg})(\mathrm{sd})$ & $143.9(21.6)$ & $141.4(17.9)$ & $142.7(19.9)$ \\
\hline $\mathrm{DBP}(\mathrm{mm} \mathrm{Hg})(\mathrm{sd})$ & $78.8(12.3)$ & 78.7 (10.9) & $78.8(11.6)$ \\
\hline $\begin{array}{l}\text { Total cholesterol } \\
(\mathrm{mmol} / \mathrm{L})(\mathrm{sd})\end{array}$ & $4.33(0.95)$ & $4.48(1.0)$ & $4.42(0.98)$ \\
\hline $\mathrm{LDL}(\mathrm{mmol} / \mathrm{L})(\mathrm{sd})$ & $2.37(0.78)$ & $2.52(0.95)$ & $2.47(0.87)$ \\
\hline Proteinuria*** $(\%)$ & 85.7 & 66.7 & 67.7 \\
\hline Diuretics (\%) & 44.1 & 55.7 & 50.4 \\
\hline Protein-restricted diet (\%) & 73.1 & 80.3 & 76.9 \\
\hline Allopurinol (\%) & 29.4 & 4.9 & 18.2 \\
\hline
\end{tabular}

PKD = Primary kidney disease, $\mathrm{BMI}=$ Body Mass Index, CVD = Cardiovascular disease, $\mathrm{SBP}=$ systolic blood pressure, $\mathrm{DBP}=$ diastolic blood pressure, $\mathrm{LDL}=$ low-density lipoprotein.

*As diagnosed by a physician.

**in $\mathrm{ml} / \mathrm{min} / 1.73 \mathrm{~m}^{3}$.

***defined as $>300 \mathrm{mg} /$ day in urine.

\section{Decline in renal function}

The patients had on average 3.46 (1.80) measurements of eGFR during follow-up. For 125 patients an eGFR measurement was available at baseline and the mean (SD) eGFR for these patients was $16.6(5.7) \mathrm{ml} / \mathrm{min} / 1.73 \mathrm{~m}^{2}$. The mean decline in renal function was $-1.61 \mathrm{ml} / \mathrm{min} /$ $1.73 \mathrm{~m}^{2} /$ year $(95 \% \mathrm{CI}-2.01,-1.22)$; indicating a loss in renal function over time.

Each $\mathrm{mg} / \mathrm{dl}$ higher UA level at baseline was associated with a change in the rate of decline in renal function of $-0.14 \mathrm{ml} / \mathrm{min} / 1.73 \mathrm{~m}^{2} /$ year $(95 \%$ CI $-0.61,0.33)$. After adjustment for age, sex, ethnicity, primary kidney disease (PKD), comorbidities (CVD, DM, hypertension), BMI, protein restricted diet, systolic blood pressure (model 1) each $\mathrm{mg} / \mathrm{dl}$ higher UA level at baseline was associated with a change in the rate of decline in renal function 
of $-0.05 \mathrm{ml} / \mathrm{min} / 1.73 \mathrm{~m}^{2} /$ year $(95 \% \mathrm{CI}-0.56,0.47)$. Additional adjustment for LDL, cholesterol, proteinuria, diuretic use, and allopurinol use (model 2) again resulted in an associated change in decline in renal function of $-0.14 \mathrm{ml} /$ $\mathrm{min} / 1.73 \mathrm{~m}^{2} /$ year $(95 \% \mathrm{CI}-0.70,0.42)$ per $\mathrm{mg} / \mathrm{dl} \mathrm{UA}$ (Table 2).

\section{Time until start of dialysis}

Seventy-one (54.2\%) patients started dialysis during follow up. Hemodialysis was modality of choice for 40 (56.3\%) patients, the remaining 31 (43.7\%) patients started with peritoneal dialysis. During pre-dialysis care 9 (6.8\%) patients died. Eighteen (13.7\%) patients were lost to followup; $9(50.0 \%)$ of which had a UA level above the median level. Thirteen $(9.9 \%)$ patients were still on pre-dialysis care at the end of follow up (February 12, 2013). Median follow-up time was 16.4 (IQR 7.7-25.4) and 20.4 (IQR 7.632.3) months for patients with UA levels above the median and below the median level, respectively. Figure 1 shows the Kaplan-Meier curves for those two patient groups. Patients showed a higher probability for starting dialysis if UA levels were above the median level at baseline.

The crude Cox proportional hazards analysis resulted in a HR for starting dialysis of 1.08 (95\% CI $0.94-1.24$; $\mathrm{p}=0.27$ ) for each $\mathrm{mg} / \mathrm{dl}$ higher UA level at baseline. Adjustment for variables in model 1 resulted in a HR for starting dialysis of 1.18 (95\% CI $1.01-1.38 ; \mathrm{p}=0.041)$. Additional adjustment for variables in model 2 increased the HR for starting dialysis to 1.26 (95\% CI 1.06 - 1.49; $\mathrm{p}=0.009)($ Table 3).

\section{Sensitivity analyses}

Our sensitivity analyses showed robustness of results. First, results for LMM and Cox proportional hazards analyses without imputation of missing data were similar to and in line with the results based on the imputed data. Second, we dichotomized based on normal UA levels in men and women. Results did not change for different UA categories in any of the analyses. Third, adding baseline eGFR to the multivariable models did not substantially change results.

Table 2 Linear mixed model for the annual rate of decline in renal function

\begin{tabular}{ll}
\hline $\begin{array}{l}\text { Mean decline in eGFR } \\
\left(\mathrm{ml} / \mathrm{min} / 1.73 \mathrm{~m}^{2}\right)\end{array}$ & $-1.61(95 \% \mathrm{Cl}-2.01 ;-1.22)$
\end{tabular}

Change in decline in eGFR per $\mathrm{mg} / \mathrm{dl}$ increase in UA at baseline

\begin{tabular}{ll}
\hline Crude $(n=129)$ & $-0.14(95 \% \mathrm{Cl}-0.61 ; 0.33)$ \\
Adjusted for Model $1(n=129)$ & $-0.05(95 \% \mathrm{Cl}-0.56 ; 0.47)$ \\
Adjusted for Model $2(n=129)$ & $-0.14(95 \% \mathrm{Cl}-0.70 ; 0.42)$ \\
\hline
\end{tabular}

Model 1 = Age, sex, ethnicity, PKD, BMI, CVD, hypertension, DM, protein restricted diet, SBD.

Model 2 = Model $1+\mathrm{LDL}$, cholesterol, proteinuria, diuretics, allopurinol.

\section{Discussion}

Our study investigated the rate of decline in renal function and time until start of dialysis associated with each $\mathrm{mg} / \mathrm{dl}$ higher UA level. Crude analyses showed that each $\mathrm{mg} / \mathrm{dl}$ higher UA level was associated with a 1.08-fold higher rate of starting dialysis. After extensive adjustment for potential confounding the HR increased to 1.26. Our analyses showed that UA levels at baseline were not associated with the rate of decline in renal function.

\section{Uric acid and decline in renal function}

Previous animal studies have shown that UA can lead to glomerular hypertension, elevated renal vascular resistance, reduced renal blood flow [26-28], activation of renin-angiotensin system (RAS), arteriolosclerosis, glomerular hypertrophy, glomerulosclerosis, and interstitial disease $[29,30]$ by inducing oxidative stress and endothelial dysfunction indicating that UA could contribute to renal damage.

Several studies have been conducted on the relation between baseline UA levels and the decline in renal function, but data in patients with CKD stage IV-V are limited. Kuo et al. studied the association between hyperuricemia and annual decline in eGFR in 63,758 patients with an initial eGFR $\geq 60 \mathrm{ml} / \mathrm{min} / 1.73 \mathrm{~m}^{2}$ and no gout in Taiwan [14]. The patients with hyperuricemia $(n=11,869)$ had an annual decline of eGFR that was almost twice as high as patients with normouricemia, 2.5 vs. $1.3 \mathrm{ml} / \mathrm{min} / 1.73 \mathrm{~m}^{2}$. Bellomo et al. followed 824 healthy people for 5 years and found that UA is an independent risk factor for GFR decrease [12]. Zhang et al. also investigated the association between UA levels and GFR decline in 1,410 healthy participants with baseline eGFR $>60 \mathrm{ml} / \mathrm{min} / 1.73 \mathrm{~m}^{2}$ in Beijing, China. Results showed that each $\mathrm{mg} / \mathrm{dl}$ increase at baseline is associated with 19\% more risk for GFR decline [15]. Obermayr et al. followed 21,475 healthy volunteers for 7 years in order to examine the association between hyperuricemia and the development of newonset kidney disease, which was defined as eGFR $<60$ $\mathrm{ml} / \mathrm{min} / 1.73 \mathrm{~m}^{2}$. After adjustment, patients in the third tertile $(\mathrm{UA} \geq 9.0 \mathrm{mg} / \mathrm{dl}$ ) had a 2.49 times higher risk of developing CKD (stage III; eGFR $<60 \mathrm{ml} / \mathrm{min} / 1.73 \mathrm{~m}^{2}$ ) [13]. Weiner et al. performed a similar study in 13,338 participants of the Atherosclerosis Risks in Communities study or the Cardiovascular Health Study. Those patients were followed for an average of 8.5 years and had intact renal function. Adjusted results showed that each $\mathrm{mg} / \mathrm{dl}$ increase in UA level led to a 1.07 times higher risk of getting CKD (stage III; eGFR $<60 \mathrm{ml} /$ $\mathrm{min} / 1.73 \mathrm{~m}^{2}$ ) [31]. Sturm et al. studied the association between UA levels and CKD progression in 177 nondiabetic CKD patients (stage I-V) that were followed for seven years. They found that UA was not predictive 


\section{Hyperuricemics vs. normouricemics}

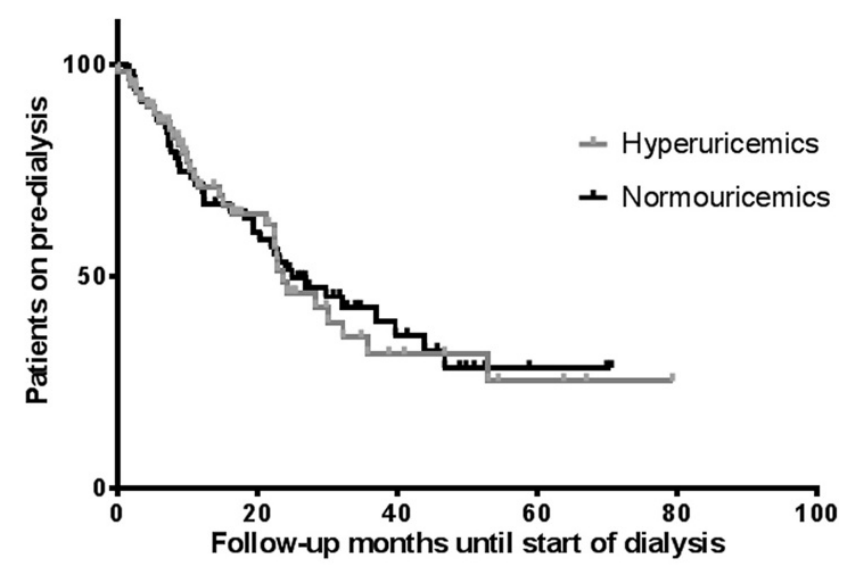

$\begin{array}{lllccl}\text { Events/nr at risk } & & & & & \\ \text { Hyperuricemics } & 0 / 60 & 19 / 26 & 30 / 7 & 31 / 3 & 31 / 0 \\ \text { Normouricemics } & 0 / 69 & 26 / 36 & 37 / 11 & 39 / 2 & 39 / 0\end{array}$

Figure 1 Kaplan-Meier for start of dialysis between hyperuricemics versus normouricemics.

for CKD progression. However, in analyses excluding patients using UA lowering drugs all results pointed towards a faster progression in patients with high levels of UA [32]. In the MDRD study the associations between UA at baseline and all-cause mortality, CVD mortality and kidney failure were studied in CKD stages III-IV patients. In this study tertiles of UA were not associated with kidney failure [33].

Except for the last two studies, the patients included were healthier or had less severe CKD compared with the patients in our study. These studies demonstrated an association between UA at baseline and the rate of decline in renal function, whereas this association was not present in the last two studies and our study. This suggests that the effects of UA levels at baseline on the rate of decline in renal function differ between CKD stages.

\section{Uric acid and start of dialysis}

High UA levels at baseline were associated with a shorter time until start of dialysis. Since UA was not associated

Table 3 Cox proportional hazards model for time until start of dialysis

\begin{tabular}{ll}
\hline \multicolumn{2}{c}{ UA per $\mathbf{~ m g} / \mathbf{d l}$ increase at baseline } \\
\hline Crude HR $(n=131)$ & $1.08(95 \% \mathrm{Cl} 0.94 ; 1.24)$ \\
Adjusted HR model $1(n=131)$ & $1.18(95 \% \mathrm{Cl} 1.00 ; 1.38)$ \\
Adjusted HR model $2(n=131)$ & $1.26(95 \% \mathrm{Cl} 1.06 ; 1.50)$ \\
\hline
\end{tabular}

Model 1 = Age, sex, ethnicity, PKD, BMI, CVD, hypertension, DM, protein restricted diet, SBD.

Model 2 = Model $1+\mathrm{LDL}$, cholesterol, proteinuria, diuretics, allopurinol. with decline in renal function in our cohort, this association might be explained by clinical symptoms such as gout that relate to UA accumulation. Gout is caused by deposition of UA crystals in the joints, most notably in the metatarsal-interphalangeal joint of the big toe. Painful and disabling symptoms of gout arthritis could have contributed to the decision of the nephrologist and patient to start dialysis. Furthermore, another explanation could be that high levels of UA might have resulted in other symptoms or clinical conditions such as renal stones or hypertension that affect the decision to start dialysis.

\section{Strengths and limitations}

A major strength of the PREPARE-2 study is the prospective longitudinal design in which the course of renal function can be investigated. However, it has been estimated that $36-65 \%$ of people in the general population with an eGFR $<15 \mathrm{ml} / \mathrm{min} / 1.73 \mathrm{~m}^{2}$ are not treated by a nephrologist [34]. While this might hamper the generalizability of our results to all patients with an eGFR $<15 \mathrm{ml} / \mathrm{min} /$ $1.73 \mathrm{~m}^{2}$, our findings can readily be generalized to the clinical practice of pre-dialysis care. As the majority of our cohort was Caucasian (94\%), our results may be different in Afro-American, Asian, and other populations.

Our analyses focused on a subset of 131 patients with a baseline UA measurement. In theory, it is possible that these 131 patients, which might be considered a limited size sample, form a selected subgroup. However, we believe the availability of serum UA levels is independent of a patient's rate of decline in renal function or 
expected time until start of dialysis. Therefore, we believe that our 131 patients form a random sample of incident patients on pre-dialysis care. Some patients had missing data for laboratory measurements. We used the method of multiple imputation to impute these missing values for each patient, further reducing bias [25].

The PREPARE-2 study is an observational cohort study, which means that it is possible that patients with increased UA levels are treated differently because their physician feels differently about their prognosis. However, as the effect of UA on the rate of decline in renal function and time until start of dialysis in this population has not been studied before, this is unlikely to have caused bias. Moreover, in our analyses we adjusted for known risk factors for an accelerated decline in renal function and early start of dialysis, further reducing potential confounding. While other differences in treatment policies, for instance earlier start of dialysis in more recent years might have occurred, it is most likely that these were present equally in patients with high versus low UA levels.

Not unexpectedly, we found patients treated with allopurinol had lower UA levels. As we assume allopurinol had no direct or pleiotropic effects on the rate of decline in renal function or time until start dialysis, use of allopurinol is not considered a potential confounder. This was confirmed in our analysis, as removing allopurinol from model 2 showed effects which were not materially different (data not shown). Moreover, allopurinol is prescribed as preventive treatment in patients with recurrent gout, which means that physicians are unlikely to more easily prescribe allopurinol to patients that they feel are at risk to start early.

\section{Conclusion}

Higher UA levels in incident pre-dialysis patients are a risk factor for an early start of dialysis, although no association with accelerated decline in renal function was found. This may indicate that patients with higher UA levels should be referred earlier to pre-dialysis care in order to guarantee appropriate preparation for start of dialysis. In the future UA levels might guide nephrologists in assessing the optimal moment to start dialysis, because we have established that higher baseline UA levels lead to an earlier start of dialysis, independent of other factors.

Therefore, more research is needed that focuses on the association between individual patient signs, symptoms, laboratory values and survival and quality of life on dialysis. This association will be investigated in the European EQUAL study that can aid nephrologists and patients in making a more evidence based decision regarding the need to start dialysis for a specific patient. In the EQUAL study UA data will be collected.

\section{Additional file}

Additional file 1: Ethical approval Prepare-2 study.

\section{Competing interests}

The authors have had no involvements that might raise the question of bias in the work reported or in the conclusions, implications, or opinions stated. None of the sponsors were involved in study design, collection of data, statistical analyses, interpretation of data, writing of the manuscript, or in the decision to submit the paper for publication. The results presented in this paper have not been published previously in whole or part, except in abstract format.

\section{Authors' contributions}

$\mathrm{HN}$ performed the statistical analyses and drafted the manuscript. MvD, MCMdG, $\mathrm{I}$, and FWD contributed to the conception and the design and revised the manuscript critically. All authors have given final approval for this version to be submitted.

\section{Acknowledgements}

The authors gratefully thank all patients who participated in the PREPARE-2 study. The nursing staffs of the participating centers, as well as the trial nurses and data managers from the Hans Mak Institute are gratefully acknowledged for collecting the clinical data. This study was supported by a grant from the Dutch Kidney Foundation (SB 110) and unrestricted grant from Amgen.

\section{The PREPARE-2 Study Group consists of}

I. Keur and R.T. Krediet, Amsterdam Medical Center, Amsterdam; H. Brulez, St Lucas Andreas Hospital, Amsterdam;

C.E. Douma, VU Medical Center, Amsterdam;

Y. Vermeeren and J. Barendregt, Gelre Hospital, Apeldoorn;

R. Bakker, Amphia Hospital, Breda;

H. Boom, Reinier de Graaf Gasthuis, Delft;

E. Hoogeveen, Jeroen Bosch Hospital, Den Bosch;

M. Groeneveld, Haga Hospital, The Hague;

M. den Hartog and G.W. Feith, Gelderse Vallei Hospital, Ede;

S. Konings, Catharina Hospital, Eindhoven;

G.H. Vastenburg, Scheper Hospital, Emmen;

A. Lavrijsen,Oosterschelde Hospital, Goes;

J.W. Eijgenraam, Groene Hart Hospital, Gouda;

C.F.M. Franssen, University Medical Center Groningen, Groningen;

C.A. Verburgh, Kennemer Gasthuis, Haarlem;

M.H. Hemmelder, Medical Center Leeuwarden, Leeuwarden;

Y.W.J. Sijpkens, Leiden University Medical Center, Leiden;

A. Schrander-van der Meer, Rijnland Hospital, Leiderdorp;

S. Boorsma, Laurentius Hospital, Roermond;

T. Noordzij and H. Krepel, Franciscus Hospital,Roosendaal;

Y. Schrama, St. Franciscus Gasthuis, Rotterdam;

C. Beerenhout and J. van Ampting, Maxima Medical Center, Veldhoven;

M. Ho-dac-Pannenkeet, Zaans Medical Center, Zaandam;

S.H.A. Diepeveen, Isala Klinieken, Zwolle - all in The Netherlands.

D.C. Grootendorst, Leiden University Medical Center, Leiden

M. Verduijn, Leiden University Medical Center, Leiden

M.C. de Goeij, Leiden University Medical Center, Leiden

D.J. de Jager, Leiden University Medical Center, Leiden

E.W. Boeschoten, Hans Mak Institute, Naarden, Leiden

F.W. Dekker, Leiden University Medical Center, Leiden

\section{Author details}

${ }^{1}$ Department of Clinical Epidemiology, Leiden University Medical Center, Albinusdreef 2, Leiden 2333 ZA, The Netherlands. ${ }^{2}$ Department of

Nephrology, Leiden University Medical Center, Leiden, The Netherlands.

Received: 5 February 2014 Accepted: 11 June 2014

Published: 16 June 2014

\section{References}

1. Zoccali C, Mallamaci F: Uric Acid, hypertension, and cardiovascular and renal complications. Curr Hypertens Rep 2013, 15:531-537.

2. Bose B, Badve SV, Hiremath SS, Boudville N, Brown FG, Cass A, de Zoysa JR, Fassett RG, Faull R, Harris DC, Hawley CM, Kanellis J, Palmer SC, Perkovic V, 
Pascoe EM, Rangan GK, Walker RJ, Walters G, Johnson DW: Effects of uric acid-lowering therapy on renal outcomes: a systematic review and meta-analysis. Nephrol Dial Transplant 2014, 29:406-413.

3. Tomita M, Mizuno S, Yamanaka H, Hosoda Y, Sakuma K, Matuoka Y, Odaka M, Yamaguchi M, Yosida H, Morisawa H, Murayama T: Does hyperuricemia affect mortality? A prospective cohort study of Japanese male workers. J Epidemiol 2000, 10:403-409

4. Iseki K, Ikemiya Y, Inoue T, Iseki C, Kinjo K, Takishita S: Significance of hyperuricemia as a risk factor for developing ESRD in a screened cohort. Am J Kidney Dis 2004, 44:642-650.

5. Sonoda H, Takase H, Dohi Y, Kimura G: Uric acid levels predict future development of chronic kidney disease. Am J Nephrol 2011, 33:352-357.

6. Zoppini G, Targher G, Chonchol M, Ortalda V, Abaterusso C, Pichiri I, Negri C, Bonora E: Serum uric acid levels and incident chronic kidney disease in patients with type 2 diabetes and preserved kidney function. Diabetes Care 2012, 35:99-104.

7. Siu YP, Leung KT, Tong MK, Kwan TH: Use of allopurinol in slowing the progression of renal disease through its ability to lower serum uric acid level. Am J Kidney Dis 2006, 47:51-59.

8. Kanbay M, Ozkara A, Selcoki Y, Isik B, Turgut F, Bavbek N, Uz E, Akcay A, Yigitoglu R, Covic A: Effect of treatment of hyperuricemia with allopurinol on blood pressure, creatinine clearence, and proteinuria in patients with normal renal functions. Int Urol Nephrol 2007, 39:1227-1233.

9. Grayson PC, Kim SY, LaValley M, Choi HK: Hyperuricemia and incident hypertension: a systematic review and meta-analysis. Arthritis Care Res (Hoboken) 2011, 63:102-110.

10. Feig DI, Soletsky B, Johnson RJ: Effect of allopurinol on blood pressure of adolescents with newly diagnosed essential hypertension: a randomized trial. JAMA 2008, 300:924-932.

11. Agarwal V, Hans N, Messerli FH: Effect of allopurinol on blood pressure: a systematic review and meta-analysis. J Clin Hypertens (Greenwich) 2013, 15:435-442.

12. Bellomo G, Venanzi S, Verdura C, Saronio P, Esposito A, Timio M: Association of uric acid with change in kidney function in healthy normotensive individuals. Am J Kidney Dis 2010, 56:264-272.

13. Obermayr RP, Temml C, Gutjahr G, Knechtelsdorfer M, Oberbauer R, Klauser-Braun R: Elevated uric acid increases the risk for kidney disease. J Am Soc Nephrol 2008, 19:2407-2413.

14. Kuo CF, Luo SF, See LC, Ko YS, Chen YM, Hwang JS, Chou IJ, Chang HC, Chen HW, Yu KH: Hyperuricaemia and accelerated reduction in renal function. Scand I Rheumatol 2011, 40:116-121.

15. Zhang L, Wang F, Wang X, Liu L, Wang H: The association between plasma uric acid and renal function decline in a Chinese populationbased cohort. Nephrol Dial Transplant 2012, 27:1836-1839.

16. Park JT, Kim DK, Chang TI, Kim HW, Chang JH, Park SY, Kim E, Kang SW, Han DS, Yoo TH: Uric acid is associated with the rate of residual renal function decline in peritoneal dialysis patients. Nephrol Dial Transplant 2009, 24:3520-3525.

17. Tattersall J, Martin-Malo A, Pedrini L, Basci A, Canaud B, Fouque D, Haage P, Konner K, Kooman J, Pizzarelli F, Tordoir J, Vennegoor M, Wanner C, ter Wee P, Vanholder R: EBPG guideline on dialysis strategies. Nephrol Dial Transplant 2007, 22(Suppl 2):ii5-ii21.

18. Dutch Federation of Nephrology: Multidisciplinary guidelines pre-dialysis. 2011.

19. K/DOQI clinical practice guidelines for chronic kidney disease: evaluation, classification, and stratification. Am J Kidney Dis 2002, 39:S1-S266.

20. Section I: Measurement of renal function, when to refer and when to start dialysis. Nephrol Dial Transplant 2002, 17(Suppl 7):7-15.

21. Levey AS, Stevens LA, Schmid CH, Zhang YL, Castro AF III, Feldman HI, Kusek JW, Eggers P, Van Lente F, Greene T, Coresh J: A new equation to estimate glomerular filtration rate. Ann Intern Med 2009, 150:604-612.

22. FitzMaurice GM: Laird NM. Hoboken, New Jersey: John Wiley \& Sons, Inc; 2011.

23. Kaplan EL, Meier P: Nonparametric estimation from incomplete observations. J Am Stat Assoc 1958, 53(282):457-481

24. Cox DR: Regression models and life-tables. J Royal Stat Soc 1972 34(2):187-220. Series B (Methodological).

25. de Goeij MC, Van DM, Jager KJ, Tripepi G, Zoccali C, Dekker FW: Multiple imputation: dealing with missing data. Nephrol Dial Transplant 2013, 28(2):2415-2420
26. Sanchez-Lozada LG, Tapia E, Santamaria J, Avila-Casado C, Soto V, Nepomuceno T, Rodriguez-Iturbe B, Johnson RJ, Herrera-Acosta J: Mild hyperuricemia induces vasoconstriction and maintains glomerular hypertension in normal and remnant kidney rats. Kidney Int 2005, 67:237-247.

27. Sanchez-Lozada LG, Tapia E, Lopez-Molina R, Nepomuceno T, Soto V, Avila-Casado C, Nakagawa T, Johnson RJ, Herrera-Acosta J, Franco M: Effects of acute and chronic L-arginine treatment in experimental hyperuricemia. Am J Physiol Renal Physiol 2007, 292:F1238-F1244.

28. Sanchez-Lozada LG, Soto V, Tapia E, Avila-Casado C, Sautin YY, Nakagawa T, Franco M, Rodriguez-Iturbe B, Johnson RJ: Role of oxidative stress in the renal abnormalities induced by experimental hyperuricemia. Am J Physiol Renal Physiol 2008, 295:F1134-F1141.

29. Mazzali M, Hughes J, Kim YG, Jefferson JA, Kang DH, Gordon KL, Lan HY, Kivlighn S, Johnson RJ: Elevated uric acid increases blood pressure in the rat by a novel crystal-independent mechanism. Hypertension 2001, 38:1101-1106

30. Nakagawa T, Mazzali M, Kang DH, Kanellis J, Watanabe S, Sanchez-Lozada LG, Rodriguez-Iturbe B, Herrera-Acosta J, Johnson RJ: Hyperuricemia causes glomerular hypertrophy in the rat. Am J Nephrol 2003, 23:2-7.

31. Weiner DE, Tighiouart $H$, Elsayed EF, Griffith JL, Salem DN, Levey AS: Uric acid and incident kidney disease in the community. J Am Soc Nephrol 2008, 19:1204-1211.

32. Sturm G, Kollerits B, Neyer U, Ritz E, Kronenberg F: Uric acid as a risk factor for progression of non-diabetic chronic kidney disease? The Mild to Moderate Kidney Disease (MMKD) Study. Exp Gerontol 2008, 43:347-352.

33. Madero M, Sarnak MJ, Wang X, Greene T, Beck GJ, Kusek JW, Collins AJ, Levey AS, Menon V: Uric acid and long-term outcomes in CKD. Am J Kidney Dis 2009, 53:796-803.

34. John R, Webb M, Young A, Stevens PE: Unreferred chronic kidney disease: a longitudinal study. Am J Kidney Dis 2004, 43:825-835.

doi:10.1186/1471-2369-15-91

Cite this article as: Nacak et al.: Uric acid: association with rate of renal function decline and time until start of dialysis in incident pre-dialysis patients. BMC Nephrology 2014 15:91.

\section{Submit your next manuscript to BioMed Central and take full advantage of:}

- Convenient online submission

- Thorough peer review

- No space constraints or color figure charges

- Immediate publication on acceptance

- Inclusion in PubMed, CAS, Scopus and Google Scholar

- Research which is freely available for redistribution 